\title{
THE KINETICS AND MECHANISMS OF REACTIONS OF HUMAN TOOTH ENAMEL IN BUFFERED SOLUTIONS OF HIGH FLUORIDE CONCENTRATIONS
}

\author{
W. I. Higuchi, S. C. VALVANI* and J. J. HefFerReN \\ College of Pharmacy, University of Michigan, Ann Arbor. Mich. 48104 and American Dental \\ Association, Chicago, 111. 60611. U.S.A.
}

\begin{abstract}
Summary-The experimental results were quantitatively compared with the theory based on a physical model representing the reaction and with the experiments involving synthetic hydroxyapatite discs. The experimental initial rates self-consistently compared well with the theoretical predictions. An analysis of the experimental initial rate data yielded a reaction constant, $k$, for the reaction representing apatite dissolution and calcium fluoride precipitation. It is proposed that the value for $k$ is a result of both supersaturation with respect to calcium fluoride and undersaturation with respect to apatite at the apatite-calcium fluoride reaction sites. This finding is also consistent with the analysis of the experiments with synthetic apatite discs.

Important similarities and significant differences were found between the experiments with the enamel sections and with synthetic apatite discs. The experiments with the synthetic apatite discs were reported to proceed "normally" as predicted by the physical model over the entire course of the reaction. In contrast to these findings, while the initial rates of the enamel-fluoride reaction were found to proceed relatively rapidly and according to the theoretical predictions, the rates at later times were drastically reduced. This "choking off" was observed to be most severe in the experiments at low $\mathrm{pH}$ and high fluoride concentrations, and little or no "choking off" was observed at low fluoride concentrations and high $\mathrm{pH}$.
\end{abstract}

\section{INTRODUCTION}

The purpose of this communication is to present the results of a study on the kinetics of the reactions between human dental enamel and fluoride at relatively high concentrations in acidic buffers. In evaluating the experimental data, special emphasis has been placed upon the use of a physical model (Nelson and Higuchi, 1970) which assumes that calcium fluoride is the principal reaction product. This model was previously examined and tested in experiments (Nelson and Higuchi, 1970; Liang and Higuchi, 1973) utilizing compressed pellets of synthetic hydroxyapatite as a model substance.

\section{MATERIALS AND METHODS}

\section{"Fluorapatite-calcium fluoride" model}

A physical model for the rate of reaction of a hydroxyapatite and/or a tooth enamel surface with fluoride at high concentrations was recently proposed (Nelson and Higuchi, 1970; Liang and Higuchi, 1973). This

* Present address: The Upjohn Company, Pharmacy Research. Kalamazoo, Mich. 49001, L.S.A. model is shown in Fig. 1 and may be described in the following way. When enamel is exposed to a solution of high fluoride concentration in a well-stirred system, the fluoride, hydrogen ions and acid buffer molecules diffuse toward the enamel surface across a liquid diffusion layer of constant thickness. When the enamel mineral begins to dissolve as a result of the acid action. calcium huoride may precipitate and deposit upon the

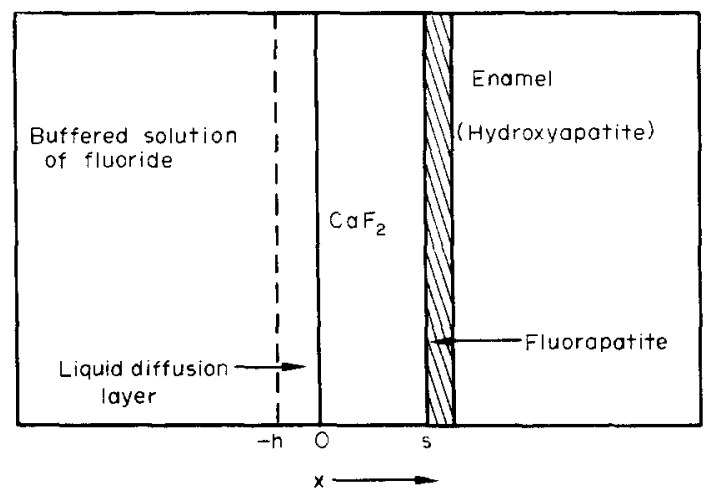

Fig. 1. Physical model describing the reaction of tooth enamel in buffered solutions of high fluoride concentrations. 
surface. Simultaneously, the products of this reaction, viz. the phosphate species and the buffer anion, begin their outward diffusion into the bulk solution. A steady state condition is rapidly attained in which the flux of fluoride ions becomes equal to the rate of fluoride precipitation as calcium fluoride. The transfer resistances for the diffusion controlled reaction is determined by both the diffusional resistance of the liquid diffusion layer and the diffusional resistance of the calcium fluoride layer of thickness, s. An important assumption in the model was that the apatite-to-calcium fluoride conversion reaction occurs completely at $x=s$ and that the reacting apatite phase at $x=s$ is fluorapatite. This effective fluorapatite phase may arise from hydroxyapatite surface exchange of the hydroxyl ions with fluoride ions (Mir, et al., 1969: Liang and Higuchi. 1973) rather than hydroxyapatite.

Assuming steady state diffusion for all the diffusing species in the region $-h \leq x \leq s$ and following Fick's first law of diffusion for the flux. $J$, per unit area of cross section, per unit time, the following expressions can be written:

$$
\begin{aligned}
& J_{\text {hutfier }}=-D_{\mathrm{HB}} \frac{\mathrm{d}(\mathrm{HB})}{\mathrm{d} x}-D_{\mathbf{B}} \frac{\mathrm{d}\left(\mathbf{B}^{-}\right)}{\mathrm{d} x} \\
& J_{\text {total phosphate }}=-D_{\mathrm{H}_{3} \mathrm{PO}_{4}} \frac{\mathrm{d}\left(\mathrm{H}_{3} \mathrm{PO}_{4}\right)}{\mathrm{d} x} \\
& -D_{\mathrm{HPO}_{4}} \frac{\mathrm{d}\left(\mathrm{H}_{2} \mathrm{PO}_{4}^{-}\right)}{\mathrm{d} x} \\
& -D_{\mathrm{HPO}_{+}} \frac{\mathrm{d}\left(\mathrm{HPO}_{4}^{2-}\right)}{\mathrm{d} x}-D_{\mathrm{PO}_{4}} \frac{\mathrm{d}\left(\mathrm{PO}_{4}^{3-}\right)}{\mathrm{d} x} \\
& J_{\text {total acid }}=-D_{\mathrm{H}} \frac{\mathrm{d}\left(\mathrm{H}^{+}\right)}{\mathrm{d} x}-D_{\mathrm{HB}} \frac{\mathrm{d}(\mathrm{HB})}{\mathrm{d} x}-D_{\mathrm{HF}} \frac{\mathrm{d}(\mathrm{HF})}{\mathrm{d} x} \\
& -D_{\mathrm{HF}_{2}} \frac{\mathrm{d}\left(\mathrm{HF}_{2}^{-}\right)}{\mathrm{d} x}-D_{\mathrm{HPO}_{4}} \frac{\mathrm{d}\left(\mathrm{HPO}_{4}^{2-}\right)}{\mathrm{d} x} \\
& -2 D_{\mathrm{H}_{2}, \mathrm{PO}_{4}} \frac{\mathrm{d}\left(\mathrm{H}_{2} \mathrm{PO}_{4}^{-}\right)}{\mathrm{d} x} \\
& -3 D_{\mathrm{H}_{3} \mathrm{PO}_{4}} \frac{\mathrm{d}\left(\mathrm{H}_{3} \mathrm{PO}_{4}\right)}{\mathrm{d} x} \\
& J_{\text {total lluoride }}=-D_{\mathrm{HF}} \frac{\mathrm{d}(\mathrm{HF})}{\mathrm{d} x}-D_{\mathrm{F}} \frac{\mathrm{d}\left(\mathrm{F}^{-}\right)}{\mathrm{d} x} \\
& -2 D_{\mathrm{HF}} \frac{\mathrm{d}\left(\mathrm{HF}_{2}^{-}\right)}{\mathrm{d} x}
\end{aligned}
$$

The $D$ 's are the effective diffusion coefficient [the use of an effective diffusion coefficient and the influence of electrical diffusion potential have been discussed elsewhere (Liang, 1973)] for the species indicated by their subscripts. The concentrations of varinus species are represented by closed brackets. $\mathrm{HB}$ and $\mathrm{B}^{-}$denote the two forms of the buffer.

$$
\begin{array}{ll}
\mathrm{HB} \rightleftarrows \mathrm{H}^{+}+\mathrm{B}^{-} & K_{\mathrm{HB}}=\frac{\left(\mathrm{H}^{+}\right)\left(\mathrm{B}^{-}\right)}{(\mathrm{HB})} \\
\mathrm{H}_{3} \mathrm{PO}_{4} \rightleftarrows \mathrm{H}^{+}+\mathrm{H}_{2} \mathrm{PO}_{4}^{-} & K_{\mathrm{P}}=\frac{\left(\mathrm{H}^{+}\right)\left(\mathrm{H}_{2} \mathrm{PO}_{4}^{-}\right)}{\left(\mathrm{H}_{3} \mathrm{PO}_{4}\right)} \\
\mathrm{H}_{2} \mathrm{PO}_{4}^{-} \rightleftarrows \mathrm{H}^{+}+\mathrm{HPO}_{4}^{2-} & K_{2 \mathrm{P}}=\frac{\left(\mathrm{H}^{+}\right)\left(\mathrm{HPO}_{4}^{2-}\right)}{\left(\mathrm{H}_{2} \mathrm{PO}_{4}^{-}\right)} \\
\mathrm{HPO}_{4}^{2-} \rightleftarrows \mathrm{H}^{+}+\mathrm{PO}_{4}^{3-} & K_{3 \mathrm{P}}=\frac{\left(\mathrm{H}^{+}\right)\left(\mathrm{PO}_{4}^{2-}\right)}{\left(\mathrm{HPO}_{4}^{2-}\right)} \\
\mathrm{HF} \rightleftarrows \mathrm{H}^{+}+\mathrm{F}^{-} & K_{\mathrm{HF}}=\frac{\left(\mathrm{H}^{+}\right)\left(\mathrm{F}^{-}\right)}{(\mathrm{HF})} \\
\mathrm{HF}+\mathrm{F}^{-} \rightleftarrows \mathrm{HF}_{2}^{-} & K_{\mathrm{HF}_{3}}=\frac{\left.(\mathrm{HF})_{2}^{-}\right)}{(\mathrm{HF})\left(\mathrm{F}^{-}\right)}
\end{array}
$$

The net flow of buffer can be considered zero since it does not take part in the reaction per se, hence,

$$
J_{\text {buffer }}=0
$$

The following relationships can be deduced from the consideration of the reaction of hydroxyapatite with fluoride to form calcium fluoride:

$$
\begin{gathered}
\mathrm{Ca}_{10}\left(\mathrm{PO}_{4}\right)_{6}(\mathrm{OH})_{2}+20 \mathrm{~F}^{-}+2 \mathrm{H}^{+} \\
\rightarrow 10 \mathrm{CaF}_{2}+6 \mathrm{PO}_{4}^{3-}+2 \mathrm{H}_{2} \mathrm{O} \\
20 J_{\text {total phosphate }}=6 J_{\text {total fluoride }} \\
20 J_{\text {total acid }}=2 J_{\text {total fluoride }}
\end{gathered}
$$

Combining the equations (1-5), (7), and (8) and eliminating $\mathrm{d} x$, the following set of equations, in differential form, can be obtained.

$$
\begin{aligned}
& \quad \mathrm{D}_{\mathrm{HB}} \mathrm{d}(\mathrm{HB})+D_{\mathrm{B}} \mathrm{d}\left(\mathrm{B}^{-}\right)=0 \\
& D_{\mathrm{H}_{3} \mathrm{PO}_{4}} \mathrm{~d}\left(\mathrm{H}_{3} \mathrm{PO}_{4}\right)+D_{\mathrm{H}_{2} \mathrm{PO}_{4}} \mathrm{~d}\left(\mathrm{H}_{2} \mathrm{PO}_{4}^{-}\right) \\
& +D_{\mathrm{HPO}_{4}} \mathrm{~d}\left(\mathrm{HPO}_{4}^{2-}\right)+D_{\mathrm{PO}_{4}} \mathrm{~d}\left(\mathrm{PO}_{4}^{3-}\right) \\
& =-0 \cdot 3\left[D_{\mathrm{F}} \mathrm{d}\left(\mathrm{F}^{-}\right)+D_{\mathrm{HF}} \mathrm{d}(\mathrm{HF})+2 D_{\mathrm{HF}_{2}} \mathrm{~d}\left(\mathrm{HF}_{2}^{-}\right)\right](10) \\
& D_{\mathrm{H}} \mathrm{d}\left(\mathrm{II}^{+}\right)+D_{\mathrm{H}^{-}} \mathrm{d}(\mathrm{HB})+D_{\mathrm{HF}_{\mathrm{F}}} \mathrm{d}(\mathrm{H} \mathrm{HF}) \\
& +D_{\mathrm{HF}_{2}} \mathrm{~d}\left(\mathrm{HF}_{2}^{-}\right)+D_{\mathrm{HPO}_{4}} \mathrm{~d}\left(\mathrm{HPO}_{4}^{2-}\right) \\
& +2 D_{\mathrm{H}_{2} \mathrm{PO}_{4}} \mathrm{~d}\left(\mathrm{H}_{2} \mathrm{PO}_{4}^{-}\right)+3 D_{\mathrm{H}_{3} \mathrm{PO}_{4}} \mathrm{~d}\left(\mathrm{H}_{3} \mathrm{PO}_{4}\right) \\
& =0 \cdot 1\left[D_{\mathrm{F}} \mathrm{d}\left(\mathrm{F}^{-}\right)+D_{\mathrm{HF}} \mathrm{d}(\mathrm{HF})+2 D_{\mathrm{HF}_{2}} \mathrm{~d}\left(\mathrm{HF}_{2}^{-}\right)\right]
\end{aligned}
$$

The chemical reactions occurring in the diffusing region $h \leq x \leq s$ along with their ionization constant expressions are as follows:

The reaction between fluoride and calcium to form solid calcium fluoride has been reported to occur rapidly (Farr, et al., 1962). It was therefore originally assumed that rapid equilibrium exists between the components in solution and in the solid phases. However, investigations from this laboratory (Liang, 1971) and a recent report (McCann, 1968) seem to indicate a 
slow equilibrium for the reaction and a tendency for supersaturation of calcium fluoride and some undersaturation offluorapatite. Thisquestion will be examined in the Discussion. The solid at $x=s$ on the apatite side of solid-solid interface has been assumed to be fluorapatite in the development of the model (see Fig. 1). Thus the reaction governing the equilibrium condition at $x=s$ is,

$$
\mathrm{Ca}_{10}\left(\mathrm{PO}_{4}\right)_{6} \mathrm{~F}_{2}+18 \mathrm{~F}^{-} \rightarrow 10 \mathrm{CaF}_{2}+6 \mathrm{PO}_{4}^{3-}
$$

The equilibrium constant for the above reaction can be written as:

$$
K_{\mathrm{eq}}-\frac{K_{\mathrm{FAP}}}{K_{\mathrm{Ca}_{2}}^{10}}=\frac{\left(\mathrm{PO}_{4}^{3-}\right)_{s}^{6}}{\left(\mathrm{~F}^{-}\right)_{s}^{18}}
$$

$K_{\mathrm{FAP}}$ and $K_{\mathrm{CaF}}$ represent the concentration products for the fluoroapatite and the $\mathrm{CaF}_{2}$ phases respectively. The concentration terms with the subscript, $s$, represent the concentrations of the species at $x=s$. These would be solubility products if true phase equilibria were to exist at $X=S$.

Substituting equations (14) and (15) in equation (19), the following new constant, $k$, can be derived:

$$
\kappa=\frac{K_{\mathrm{FAP}}^{1 / 6}}{K_{\mathrm{Ca}_{2}}^{10 / 6} K_{2 \mathrm{P}} K_{3 \mathrm{P}}}=\frac{\left(\mathrm{H}_{2} \mathrm{PO}_{4}^{-}\right)_{s}}{\left(\mathrm{~F}^{-}\right)_{s}^{3}\left(\mathrm{H}^{+}\right)_{s}^{2}}
$$

Integration of the concentration of the participating species with limits from concentration at $x=-0$ to $x=s$ of the equations $(9-11)$, and subsequent combination with the equations (12-17) and (20) result in the following set of equations (Nelson, 1968; Valvani, 1970):

$$
\begin{gathered}
(Q U-M V)+\sqrt{ }[M V-Q U)^{2} \\
\left(\mathrm{~F}^{-}\right)_{s}=\frac{-4(L V-P U)(N V-R U)]}{2(L V-P U)} \\
\kappa\left(\mathrm{F}^{-}\right)_{s}^{3}\left(\mathrm{H}^{+}\right)_{s}^{2} V-P\left(\mathrm{~F}^{-}\right)_{s}^{2}-Q\left(\mathrm{~F}^{-}\right)_{s}-R=0
\end{gathered}
$$

where,

$$
\begin{aligned}
L= & -0.8 D_{\mathrm{HF}_{2}} \frac{K_{\mathrm{HF}_{2}}}{K_{\mathrm{HF}}}\left[\mathrm{H}^{+}\right]_{s} \\
M= & 0.1 D_{\mathrm{F}}-0.9 D_{\mathrm{HF}} \frac{\left[\mathrm{H}^{+}\right]_{s}}{K_{\mathrm{HF}}} \\
N= & -0.1 D_{\mathrm{F}}\left(\mathrm{F}^{-}\right)_{0}+0.9 D_{\mathrm{HF}}(\mathrm{HF})_{0} \\
& +0.8 D_{\mathrm{HF}_{2}}\left(\mathrm{HF}_{2}^{-}\right)_{0}^{-} D_{\mathrm{H}}\left(\mathrm{H}^{+}\right)_{s}+D_{\mathrm{H}}\left(\mathrm{H}^{+}\right)_{0} \\
& -D_{\mathrm{HB}} \frac{D_{\mathrm{HB}}(\mathrm{HB})_{0}+D_{\mathrm{B}}\left(\mathrm{B}^{-}\right)_{0}}{D_{\mathrm{HB}}+D_{\mathrm{B}} \frac{K_{\mathrm{HB}}}{\left(\mathrm{H}^{+}\right)_{s}}} \\
& +D_{\mathrm{HB}}\left(\mathrm{HB}_{0}+D_{\mathrm{HPO}_{4}}\left(\mathrm{HPO}_{4}^{2-}\right)_{0}\right. \\
& +2 D_{\mathrm{H}_{2} \mathrm{PO}_{4}}\left(\mathrm{H}_{2} \mathrm{PO}_{4}^{-}\right)_{0}+3 D_{\mathrm{H}_{3} \mathrm{PO}_{4}}\left(\mathrm{H}_{3} \mathrm{PO}_{4}\right)_{0} \\
P= & -0.6 D_{\mathrm{HF}_{2}} \frac{K_{\mathrm{HF}^{-}}}{K_{\mathrm{HF}}}\left(\mathrm{H}^{+}\right)_{s}
\end{aligned}
$$

$$
\begin{aligned}
Q= & -0 \cdot 3 D_{\mathrm{F}}-0 \cdot 3 D_{\mathrm{HF}} \frac{\left(\mathrm{H}^{+}\right)_{s}}{K_{\mathrm{HF}}} \\
R= & 0 \cdot 3 D_{\mathrm{F}}\left(\mathrm{F}^{-}\right)_{0}+0 \cdot 3 D_{\mathrm{HF}}(\mathrm{HF})_{0}+0 \cdot 6 D_{\mathrm{HF}_{2}}\left(\mathrm{HF}_{2}^{-}\right)_{0} \\
& +D_{\mathrm{H}_{3} \mathrm{PO}_{4}}\left(\mathrm{H}_{3} \mathrm{PO}_{4}\right)_{0}+D_{\mathrm{H}_{2} \mathrm{PO}_{4}}\left(\mathrm{H}_{2} \mathrm{PO}_{4}^{-}\right)_{0} \\
& +D_{\mathrm{HPO}_{4}}\left(\mathrm{HPO}_{4}^{2-}\right)_{0}+D_{\mathrm{PO}_{4}}\left(\mathrm{PO}_{4}^{3-}\right)_{0} \\
U= & D_{\mathrm{HPQ}_{4}} \frac{K_{2 \mathrm{P}}\left(\mathrm{H}^{+}\right)_{s}}{2}+2 D_{\mathrm{H}_{2} \mathrm{PO}_{4}}+3 D_{\mathrm{H}_{3} \mathrm{PO}_{4}} \frac{\left(\mathrm{H}^{+}\right)_{s}}{K_{\mathrm{P}}} \\
V= & D_{\mathrm{H}_{3} \mathrm{PO}_{4}} \frac{\left(\mathrm{II}^{+}\right)_{s}}{K_{\mathrm{P}}}+D_{\mathrm{H}_{2} \mathrm{PO}_{4}}+D_{\mathrm{HPO}_{+}} \frac{K_{2 \mathrm{P}}}{\left(\mathrm{H}^{+}\right)_{s}} \\
& +D_{\mathrm{PO}_{4}} \frac{K_{2 \mathrm{P}} K_{3 \mathrm{P}}}{\left(\mathrm{H}^{+}\right)_{s}^{2}}
\end{aligned}
$$

Equations (21) and (22) represent two equations in two unknowns, $\left(\mathrm{F}^{-}\right)_{\text {s }}$ and $\left(\mathrm{H}^{+}\right)$. The concentration terms with subscripts 0 are the known bulk-solution concentration of the species. The only unknowns are $\left(\mathrm{F}^{-}\right)_{s}$ and $\left(\mathrm{H}^{-}\right)_{s}$. These equations can be solved simultaneously for the system with a particular set of experimental conditions.

\section{Time dependent considerations}

The flux of total fluoride can be represented as,

$$
\begin{aligned}
J_{\text {[otal fluoride }=}=-A D_{\mathrm{F}} \frac{\mathrm{d}\left(\mathrm{F}^{-}\right)}{\mathrm{d} x}- & A D_{\mathrm{HF}} \frac{\mathrm{d}(\mathrm{HF})}{\mathrm{d} x} \\
& -2 A D_{\mathrm{HF}_{2}} \frac{\mathrm{d}\left(\mathrm{HF}_{2}\right)}{\mathrm{d} x}
\end{aligned}
$$

where, $A$ is the surface area of enamel exposed to the fluoride solution.

Assuming the diffusion coefficients of the above three species to be equal (Liang, 1971). the equation (23) can be reduced to,

$$
J_{\text {total fluoride }}=-A D \frac{\mathrm{d}(\mathrm{TF})}{\mathrm{d} x}
$$

where

$$
(\mathrm{TF})=\left(\mathrm{F}^{-}\right)+(\mathrm{HF})+2\left(\mathrm{HF}_{2}^{-}\right)
$$

The flux of total fluoride upon integration from the concentration [TF] at time $t$, to that at $x=s$, through total diffusion path yields,

$$
J_{\text {total liuoride }}=-A D \frac{(\mathrm{TF})_{s}-(\mathrm{TF})}{s+(\mathrm{h} \epsilon) / t}
$$

where, $D$ is the effective diffusion coefficient for the heterogeneous layer $o \leq x \leq s$, and $s$ the thickness, $\epsilon$, the porosity, and $\tau$, the tortuosity of the calcium fluoride layer.

Relating the rate of uptake of fluoride to the total flux of fluoride, the following is obtained.

$$
-V \frac{\mathrm{d}(\mathrm{TF})}{\mathrm{d} t}=-A D \frac{\left[(\mathrm{TF})_{\mathrm{s}}-(\mathrm{TF})\right]}{S+(h \epsilon) / \tau}
$$


A relationship for $s$ the thickness of the calcium fluoride layer can be obtained from the consideration of the amount of fluoride lost from the solution. Thus,

$$
s=\frac{19 V\left[(\mathrm{TF})_{i}-(\mathrm{TF})\right]}{A \rho}
$$

where, $[\mathrm{TF}]_{i}$ is the initial fluoride concentration. [TF]. the fluoride concentration in solution at time $t$. and $\rho$. the fluoride density in the calcium fluoride layer.

Substitution of equation (28) into equation (27), and integration from the initial concentration in the solution to the concentration at time $t$, results in the following equation.

$$
\begin{array}{r}
{\left[\frac{19 V^{2}}{A^{2} \rho D}\right]\left[(\mathrm{TF})-(\mathrm{TF})_{i}+(\mathrm{TF})_{s} \ln \frac{(\mathrm{TF})-(\mathrm{TF})_{s}}{(\mathrm{TF})_{i}-(\mathrm{TF})_{s}}\right]} \\
-\frac{19(\mathrm{TF})_{i} V^{2}}{A^{2} \rho D}+\frac{V h}{A D} \ln \frac{(\mathrm{TF})-(\mathrm{TF})_{s}}{(\mathrm{TF})_{i}-(\mathrm{TF})_{s}}=t
\end{array}
$$

The above equation represents [TF], the total fluoride concentration in solution, as a function of time. This can be used to express the amount of fluoride lost from the solution. that is the actual fluoride uptake $\ell_{1}$ in grams, by relating it to the initial fluoride concentration.

$$
l_{1}=19 l\left[(\mathrm{TFF})_{i}-(\mathrm{TF})\right]
$$

Since the analysis for phosphate in the solution relcased from the reaction was used to follow the extent of the reaction experimentally. the phosphate release, $P_{R}$, can be related to the fluoride uptake from consideration of the stoichiometry of the reaction. The phosphate release, $\mathrm{P}_{k}$ is given by,

$$
\mathrm{P}_{R}=1.5 U_{\mathrm{H}}
$$

To use the equations (29-31) for the estimation of fluoride uptake for a particular experiment, it is required to compute (TF) $)_{s}$. The equations (21) and (22) are used to calculate $\left(\mathrm{H}^{+}\right)$, and $\left(\mathrm{F}^{-}\right)$, by substituting in the equations the initial concentration of the species and the values of the parameters from Tables 1 and 2 . The equations are simultaneously solved for $\left(\mathrm{H}^{\dagger}\right)$, and $\left(\mathrm{F}^{-}\right)^{-}$. The value of $(\mathrm{TF})_{\mathrm{s}}$ is computed and put into equation (29) along with the constants. Various (TF) values are substituted into the equation (29) and the corresponding times are calculated.

\section{G'neral consideration in the design of experiments}

To ensure that critical comparison between the experiments and the physical model could be achieved. the following considerations in experiment design were made. First mainly human incisors were selected for the experiments because they generally provided large, well-defined surfaces that were reasonably flat. It was decided to cover a wide range of $\mathrm{pH}$ and fuoride concentrations so that both the "fluoride-diffusion-controlled" and the "solubility-diffusion-controlled" reg- ions (Nelson, 1968) of the model could be explored. It was also decided to conduct experiments with an artifically increased aqueous diffusion layer thickness so that "initial rate" comparison to theory could be made in addition to the usual time dependent studies.

The total fluoride concentrations at $0.05 \mathrm{M}, 0.10 \mathrm{M}$, and $0 \cdot 20 \mathrm{M}$; at $\mathrm{pH}$ values of $4 \cdot 0,4 \cdot 5,5 \cdot 0$, and $5 \cdot 5$ with $0 \cdot 10 \mathrm{M}$ and $0.20 \mathrm{M}$ total acetate buffer concentration

\begin{tabular}{|c|c|c|}
\hline $\begin{array}{l}K_{p}=6.98 \times 10^{-3} \\
K_{20}=6.40 \times 10^{-8} \\
K_{3 p}=4.73 \times 10^{13}\end{array}$ & $\begin{array}{l}K_{\mathrm{HF}} \\
K_{\mathrm{HF}}= \\
K_{\mathrm{HB}}\end{array}$ & $\begin{array}{l}=3.53 \times 10^{-4} \\
=4.0 \\
=1.75 \times 10^{5}\end{array}$ \\
\hline $\begin{array}{l}=0.55 \\
=0.23 \\
=0.095\end{array}$ & $\begin{array}{l}i_{\mathrm{H}} \\
\eta_{\mathrm{k}} \\
\eta_{\mathrm{H}}\end{array}$ & $\begin{array}{l}=0.632 \\
=0.735 \\
=0.80\end{array}$ \\
\hline
\end{tabular}
were considered for the experimental study.

Table 1. Thermodynamic constants. activity coefficients* and other parameter ${ }^{\dagger}$ values for theoretical calculations

$$
\begin{array}{ll}
D & =0.9 \times 10^{\circ} \mathrm{cm}^{2} \mathrm{sec}^{-1} \\
\tau i \epsilon & =8.0 \\
\rho^{+} & =1.155 \\
\mathrm{~h}_{+}^{+} & =37.5 \times 10^{-4} \mathrm{~cm} \\
\mathrm{~h} \S & =310 \times 10^{-4} \mathrm{~cm}
\end{array}
$$

* For ionic strength of $0.5 \mathrm{M} \mathrm{NaCl}$.

$¥$ See text for definitions of these parameters.

$\leqslant$ The liquid diffusion layer thickness was obtained by conducting dissolution rate measurements on compressed pellets of benzoic acid in $0.1 \mathrm{~N} \mathrm{HCl}$ under the

\begin{tabular}{|c|c|}
\hline $3.74 \times 10^{11}$ & $\begin{array}{l}\text { Value found by liang (1971) for syn- } \\
\text { thetic TVA hydroxyapatite reaction } \\
\text { with fluoride based on } K_{R_{A P}}=10^{-131} \\
\text { and } K_{C a F_{z}}=10^{-8.3}\end{array}$ \\
\hline $1.76 \times 10^{12}$ & $\begin{array}{l}\text { Based upon } K_{F A P}=10^{-127} \text { and } \\
K_{\mathrm{CaF}_{2}}=10^{-8 \cdot 3}\end{array}$ \\
\hline $1.76 \times 10^{13}$ & $\begin{array}{l}\text { Based upon } \\
K_{\mathrm{CaF}}=10^{-8 \cdot 3}\end{array} K_{H \mu}=10^{-121}$ \\
\hline $1 \cdot 18$ & $\begin{array}{l}\text { Based upon } K_{I_{A} P}=10^{-119} \\
K_{\mathrm{CaF}_{2}}=10^{-10 \cdot 4}\end{array}$ \\
\hline
\end{tabular}
same hydrodynamic and geometric conditions as for cnamel block situations (Valvani, 1970).

$\$$ The effective liquid diffusion layer thickness was obtained by carrying out experiments placing a silver membrane in series with the benzoic acid pellet surface (Valvani. 1970).

Table 2. $k$ values* ${ }^{*}$ as a function of $K_{F_{A} p^{\dagger}}$ and $K_{\mathrm{CaF}_{2}} \dagger$ $\kappa$ Comments

* See equation (20) for the definition of $k$.

+ These values are activity products rather than concentration products derived by correcting equation (20) with the activity coefficients. 
The enamel sections

A cylindrical plug ( 4 or $5 \mathrm{~mm}$ dia) was cut from clean human tooth with a Horico HP diamond core drill and mounted in a cylindrical brass ring with the enamel section on the surface using self curing methymethacrylate. After removal from the ring the enamel block was polished successively on a Buehler rotary polishing wheel with $240,320,400$ and 600 grit paper using water, and finally with a Burlew wheel (rubber with fine grade of pumice). Throughout the procedure, the surface of the tooth was kept moist. The whole process results in exposing the subsurface enamel. A $1 / 4$ in. dia acrylic rod was attached to the mount.

\section{Apparatus}

A jacketed glass beaker with water circulating at $30^{\circ} \mathrm{C}$ was used. A rubber stopper held the acrylic rod with enamel block and was provided with a hole for sampling. The solution was stirred by a Teflon-coated magnetic bar and a $150 \mathrm{rev} / \mathrm{min}$ constant speed motor (Bodine Motors, Chicago, Ill.). Four of these were connected in series.

\section{Preparation of huffered fluoride solutions}

The quantities of the acid and salt forms of the buffer were calculated using the Henderson-Hasselbach equation. Reagent grade sodium acetate (J. T. Baker Chemical Co.. Phillipsburg, N.J.) and acetic acid glacial (J. T. Baker Chemical Co., Phillipsburg, N.J.) were used for the buffers. Reagent grade sodium fluoride (J. T. Baker Chemical Co., Phillipsburg, N.J.) was used as the source of fluoride. All the solutions were adjusted to an ionic strength of $0.5 \mathrm{M}$ by addition of sodium chloride (J. T. Baker Chemical Co., Phillipsburg. N.J.). The $\mathrm{pH}$ of the solution was measured with a Beckman model $\mathrm{G}$ pH meter and was adjusted to $\pm 0.02 \mathrm{pH}$ units of the desired value.

\section{General experimental procedure}

Four randomly chosen enamel sections were used for each expcrimental condition and were placed in the apparatus. The sections were etched initially for $1 \mathrm{hr}$ in dilute acidic solution consisting of either a $\mathrm{pH} 4.5$, $0.1 \mathrm{M}$ acetate buffer or a $10^{-3} \mathrm{M}$ hydrochloric acid. After initial etching and brief washing with distilled water, the enamel blocks were placed in the apparatus. Ten millilitres of buffered fluoride solution were used for the reaction study. Periodically, $5 \mathrm{ml}$ of the solution was withdrawn and replaced with fresh fluoride solution. The samples were analyzed for phosphate by a modified method of Gee et al. (1954).

\section{RESULTS}

\section{General observations}

Typical experimental data (additional data covering a wider range of conditions may be found in the thesis of Valvani, 1970) are presented in Figs. 2 11. Since four enamel sections were used for a particular set of exper- imental conditions, four sets of data shown in these figures represent the experimental results from four randomly chosen enamel sections.

Some general observations can be made about these results. It is apparent that there is considerable sample to sample variation in a single experimental run. However, it can be seen that the initial points in these data are relatively close together.

No apparent change in the texture and surface of enamel sections after the reaction in buffered fluoride solutions could be observed with visual inspection or under laboratory optical microscope. Initially, the calcium fluoride layer formed was found to be quite firmly adhered to the surface. Attempts to scrape off the reacted surface were largely unsuccessful. However, after prolonged periods of storage in dry condition, it was often possible to scrape off the surface with a laboratory spatula.

The experimental rates were found to be dependent on total fluoride concentration, the $\mathrm{pH}$ of the solution. and total buffer concentration. In general, the reaction occurred to greater extent at the higher solution fluoride concentration and at lower $\mathrm{pH}$ values. The calcium fluoride layers that formed were estimated to be approximately $5 \mu \mathrm{m}$ to $60 \mu \mathrm{m}$ in thickness.

It is instructive to note that the observed initial rates per unit area were roughly of the same order of magnitude as those observed by Nelson (1968) and by Liang (1971) in their experiments with synthetic hydroxyapatite discs. The rates at later times, while they appeared to follow the "normal" patterns exhibited by the synthetic discs at high $\mathrm{pH}$ and low fluoride concentrations, were extremely low in most cases.

In a large number of cases, it was observed that relatively rapid initial reaction rates were followed by drastic reduction in the rate at later times. This type of reaction pattern was observed often in experiments at the higher fluoride concentrations and at low pH values. This apparent "choking off" was dependent on these variables. Most severe "choking off" was observed with the experiments at the lowest $\mathrm{pH}$ and the highest fluoride concentration. This "choking off" became less severe with decreasing concentration of fluoride at the same $\mathrm{pH}$.

\section{Choice of parameters in the model used in the theoretical calculations}

Since the thickness, $s$, of the calcium fluoride layer formed was so small, the usual means (Desai et al. 1965 ) for the determination of tortuosity and porosity could not be employed. However, from theoretical considerations (Higuchi and Higuchi, 1960). if the particles of calcium fluoride in the layer are assumed to form isometrically, an estimate for the tortuosity, $\tau$, of about 2.0 could be made. Also from the known values for the density and calcium content of enamel and the density of calcium fluoride, an estimate for the porosity, $c$ of about 0.25 can be made. Thus 8.0 is a reasonable estimate for the tortuosity-porosity ratio, $\tau / \epsilon$.The 
other parameters and their values used in the preliminary analysis are given in Tables 1 and 2. Most of the values given are the same as those employed by Nelson (1968) and by Liang (1971) in their work with synthetic apatites. A value of $0.9 \times 10^{-5} \mathrm{~cm}^{2} \mathrm{sec}^{-1}$ was taken for all of the diffusion coefficients. This is reasonable and consistent with those choices made by both Nelson and Liang. The activity coefficient for the bifluoride ion was assumed to be the same as that for the fluoride ion.

In Table 2. several \& values are presented which have been employed in the calculations with the theoretical equations. The $\kappa$ value of $3.74 \times 10^{11}$ is that found by Liang in his studies on the reaction of synthetic TVA hydroxyapatite with fluoride under solution conditions similar to those in the present studies. This $k$ value is based upon a $K_{F A P}$ value of $10^{-131}$ and a $K_{(\text {ial }}$ value of $10^{8.3}$. The $K_{Y, 1 P}=10^{-133}$ is the same as that found by Mir et al. (1969) and by Liang (1971) independentlyand represents the prevailing fluorapatite activity product during "rapid" reaction of TVA hydroxyapatite crystals in acidic media containing low $(\simeq 100 \mathrm{ppm})$ fluoride. The $K_{(\mathrm{ar}}, 110^{-8.3}$ was deduced (Liang. 1971) to be the prevailing calcium fluoride activity product during "rapid" precipitation of calcium fluoride upon the surface of the hydroxyapatite crystals during the reaction.

The $k$ value of $1.76 \times 10^{12}$ is based upon a $K_{\text {(al }}$ of $10^{-8.3}$ and a $K_{I A P^{p}}=10^{-127}$. The $K_{I_{A}}$, value was that determined from surface dissolution experiments (Valvani, 1970: Fawzi. 1973, personal communications) with block enamel in $10^{-3} \mathrm{M}$ fluoride (no $\mathrm{CaF}_{2}$ formation) and using the equations given by Mir 't al. (1969) for this situation.

The $k$ value of $1.76 \times 10^{1.3}$ is based upon $K_{\mathrm{CaF}}=$ $10^{-8.3}$ and $K_{t \cdot A}$ of $10^{-121}$. The latter is based upon studies of Mir at al. (1969) with powdered enamel in acidic solutions containing low fuoride $\left(\geq 10^{-3} \mathrm{M}\right)$.

Finally. the $k$ value of $1.18 \times 10^{17}$ is based upon $K_{\text {IAP }}=10^{11^{19}}$ and $K_{\mathrm{CHF}}=3.95 \times 10^{-11}$ which are activity products close to the thermodynamic solubility products (Mir et al.. 1969; Handbook. 1969). This $\&$ value would be expected to be applicable only if the reaction conditions at $x=s$ were in true equilibrium.

\section{Comparison of theoredical results with experiments}

The theoretical calculations were carried out by simultaneously solving equations (21) and (22) and using the results in equations (29-31) for initial rate computations. The ealculations were programmed and made using an IBM 360/67 digital computer (Liang, 1971) The theoretical curves calculated using the various $k$ values are shown in Figs. 2-12 along with the experimental results.

There are several noteworthy observations that can be made by comparing the theoretical calculations with the experimental results. First, when only initial rates atre considered. the $k$ value of $1.76 \times 10^{+12}$ consistently gives the best agreement between theory and

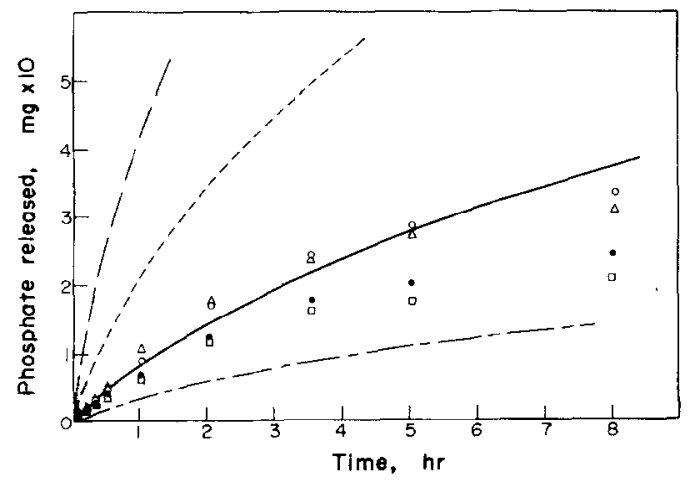

Fig. 2. Phosphate release from each of four enamel sections $\left(A=0.196 \mathrm{~cm}^{2}\right)$ on reacting with buffered solutions at $\mathrm{pH}$ 5.50. $T \mathrm{~F}=0.05 \mathrm{M}, T B=0 \cdot 10 \mathrm{M}$. Theoretical curves shown on the graph using $\tau / \epsilon=8$ and various $k$ values. For $h$ values. $\quad 3.18 \times 10^{17} ; \cdots 1.76 \times 10^{12} ; \cdots \cdots$.

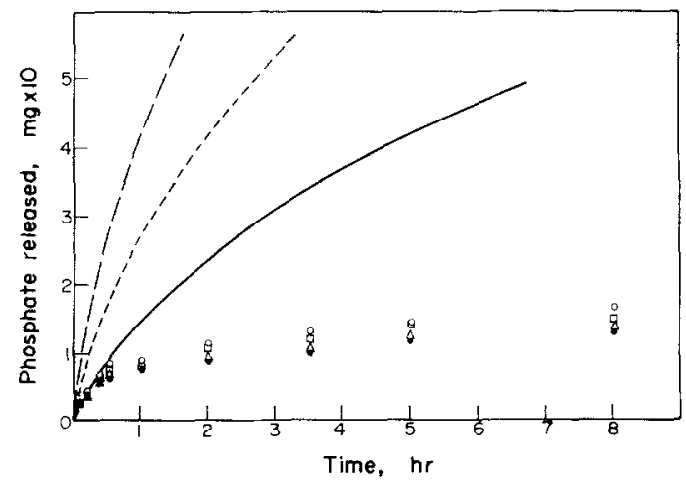

Fig. 3. Phosphate release from each of four cnamel sections $\left(A=0.125 \mathrm{~cm}^{2}\right)$ on reacting with buffered solution at $\mathrm{pH}$ 5.00. $T \mathrm{~F}=0.05 \mathrm{M} . \quad T B=0.10 \mathrm{M}$. Theoretical curves shown on the graph using $\tau / \epsilon 8$ and $\kappa$ values. For $k$ values, $1.18 \times 10^{17}: 10^{3}:$ $1.76 \times 10^{13}$

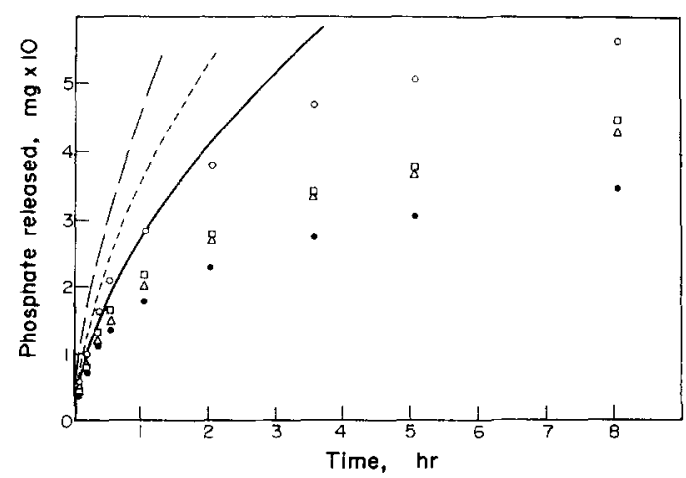

Fig. 4. Phosphate release from each of four enamel sections $\left(A=0.125 \mathrm{~cm}^{2}\right)$ on reacting with buffered solution at $\mathrm{pH}$ $4.50, \quad T F=0.05 \mathrm{M} . \quad T B=0 \cdot 10 \mathrm{M}$. Theoretical curves shown on the graph using $\tau / \epsilon=8$ and $k$ values. For $k$ values: $\quad 1.18 \times 10^{17}: \ldots 1.76 \times 10^{13}$. 


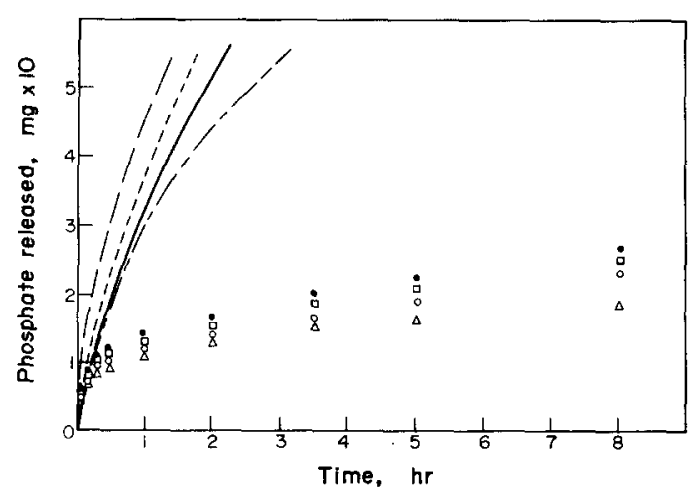

Fig. 5. Phosphate release from each of four enamel sections $\left(A=0.125 \mathrm{~cm}^{2}\right)$ on reacting with buffered solution at $\mathrm{pH}$ 4.00. $T F=0.05 \mathrm{M}, T B=0.10 \mathrm{M}$. Theoretical curves shown on the graph using $\tau / \epsilon=8$ and various $\kappa$ values. For $\kappa$ values. $-1.18 \times 10^{17} ;-1.76 \times 10^{12} ; \ldots$ $3.74 \times 10^{11} ;--1.76 \times 10^{13}$.

experiment. This is especially true at high $\mathrm{pH}$ (Figs. 2 , 6 and 10) and low fluoride (Figs. 2-4) where the reaction rates are relatively low. At high fluoride and/or low $\mathrm{pH}$ conditions, the reaction rates are relatively high and the sensitivity of the calculations to $\kappa$ are relatively poor (Figs. 5, 7 and 9). It is difficult to determine for the latter situations whether one $\kappa$ value might be better than any of the others.

When comparisons are made between theory and experiment over the entire time range, strikingly unusual patterns are found. While the early portions of the data correspond to relatively rapid reactions and good agreement with theory, the data in most cases at later times are often very greatly reduced in relation to theoretical predictions based on $\kappa=1.76 \times 10^{12}$. This effect has already been referred to as the "choking off" effect. It is noted. also, that in some instances (Figs. 2

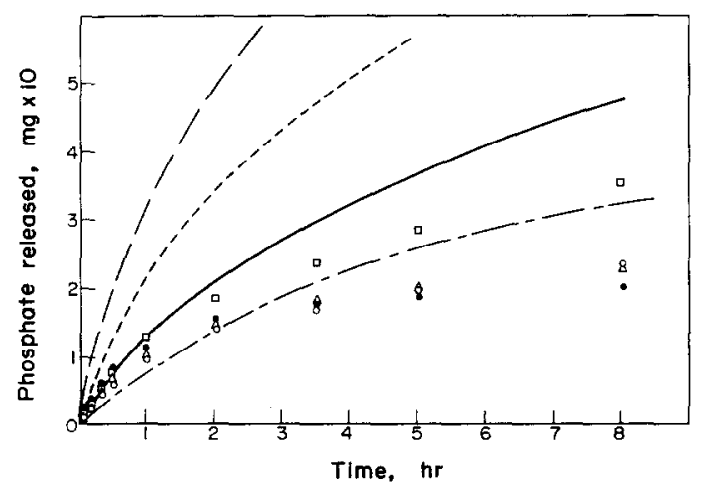

Fig. 6. Phosphate release from each of four enamel sections $\left(A=0.125 \mathrm{~cm}^{2}\right)$ on reacting with buffered solution at $\mathrm{pH}$ 5.50. $T \mathrm{~F}=0.10 \mathrm{M}, T B=0 \cdot 10 \mathrm{M}$. Theoretical curves shown on the graph using $\tau / \epsilon=8$ and various $\kappa$ values. For $\kappa$ values, $-1.18 \times 10^{17} ;-\ldots 1.76 \times 10^{12} ; \ldots .$. $3.74 \times 10^{11}:--1.76 \times 10^{13}$.

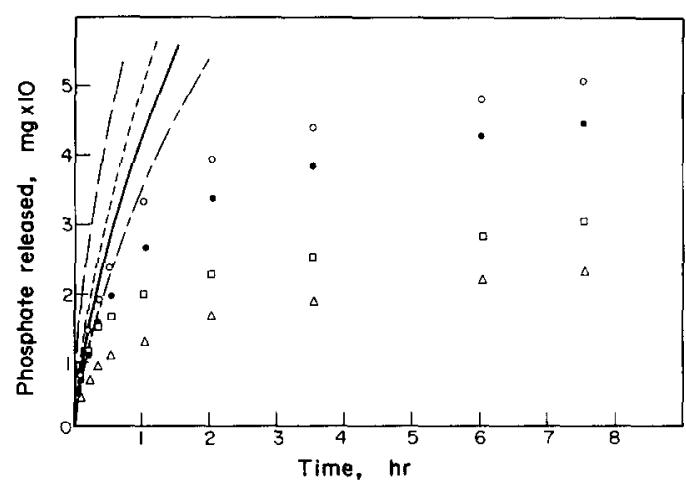

Fig. 7. Phosphate release from each of four enamel section $\left(A=0.125 \mathrm{~cm}^{2}\right)$ on reacting with buffered solution at $\mathrm{pH}$ $4 \cdot 50, \quad T F=0 \cdot 10 \mathrm{M}, \quad T B=0 \cdot 10 \mathrm{M}$. Theoretical curves shown on the graph using $\tau / \epsilon-8$ and various $\kappa$ values. For $k$ values. - - $1.18 \times 10^{17} ;-1.76 \times 10^{12} ; \ldots$ $3.74 \times 10^{11}:-1.76 \times 10^{13}$.

and 10) the agreement between theory and experiment appear to hold relatively well over the entire experiment.

It is important to consider the uncertainties in the parameter values listed in Table 1. Except for the $\tau / \epsilon$ value, the quantities in Table $I$ are all reasonable and have been examined in more ideal experimental situations (Liang, 1971; Hodes, 1972). In order to make certain that an error in the choice of the $\tau / \epsilon$ value would not greatly influence the best $\kappa$ value, selected experiments were also conducted (Valvani, 1970) with an artificial diffusion barrier placed in series with the enamel. The effective diffusion layer thickness for this membrane (silver membrane filter, Selas Flotronics, Spring House, Pa.) barrier was $h=310 \mu \mathrm{m}$.

Fig. 12 shows results of experiments at $\mathrm{pH}=5.5$ with the artificial barrier and the corresponding for

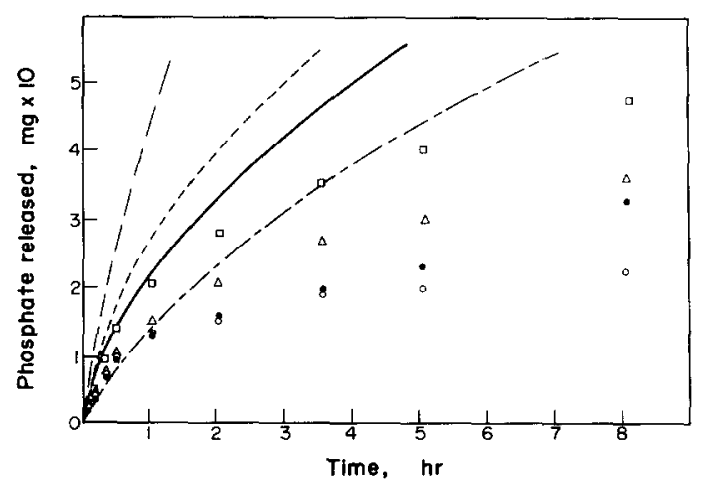

Fig. 8. Phosphate release from each of four enamel sections $\left(A=0.125 \mathrm{~cm}^{2}\right)$ on reacting with buffered fluoride solution at $\mathrm{pH} 5 \cdot 50, T \mathrm{~F}=0.20 \mathrm{M}, T B=0 \cdot 10 \mathrm{M}$. Theoretical curves shown on the graph using $\tau / \epsilon=8$ and various $\kappa$ values. For $r$ values, $\quad 1.18 \times 10^{17} ;-1.76 \times 10^{12}$; $3.74 \times 10^{11} ; \ldots 1.76 \times 10^{13}$. 


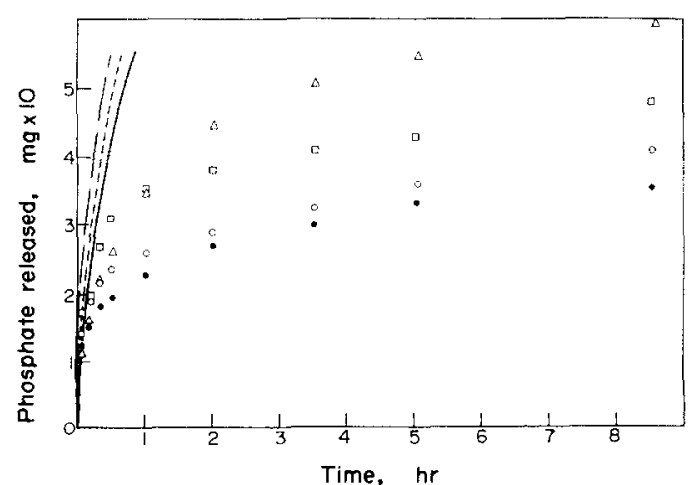

I'ig. 9. Phosphate release from cach of four cnamel sections $\left(A=0.125 \mathrm{~cm}^{2}\right)$ on reacting with buffered fluoride solution at $\mathrm{pH} 4 \cdot 50, T \mathrm{~F}=0.20 \mathrm{M}, T B=0.10 \mathrm{M}$. Theoretical curves shown on the graph using $r / \epsilon=8$ and $k$ values. For $k$ values. $1.18 \times 10^{17}:-1.76 \times 10^{12}$ :

$$
1.76 \times 10^{13} \text {. }
$$

theoretical results. The good agreement between experiment and theory support the value of $\kappa=$ $1.76 \times 10^{12}$ determined without the artificial barrier.

\section{DISCLSSION}

The meaning of $k=1.76 \times 10^{12}$

A $r$ value of around $1.76 \times 10^{12}$ is indeed reasonable in light of the studies with synthetic TVA hydroxyapatite. With the TVA sample a $k$ value of $3.74 \times 10^{11}$ was obtained which differs somewhat from the best valuc obtained in the present work with block enamel. From independent experiments, however. the $K_{A A P}$ for the TVA material (Mir ef al., 1969 ; Liang, 1971) was determined to be about $10^{4}$ to $10^{5}$ times smaller than what has been found for the surface of block enamel (Valvani. 1970). Therefore, if the larger but probably more appropriate value for $K_{r A A}$, is used for the enamel situation the initial rate enamel data are

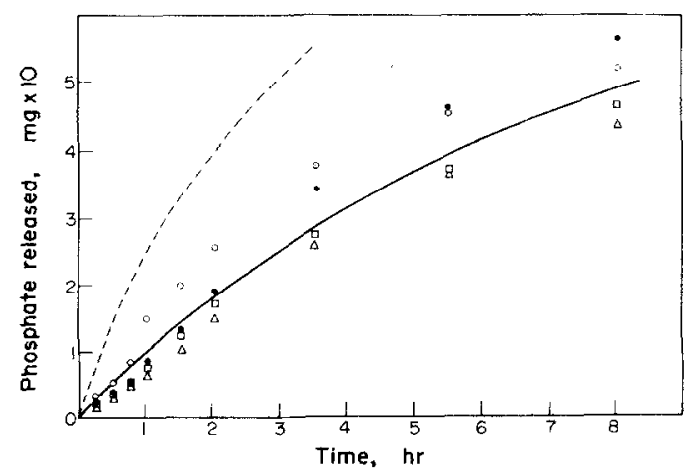

Fig. 10. Phosphate releasc from each of four enamel sections $\left(A=0.196 \mathrm{~cm}^{2}\right.$ ) on reacting with buffered fluoride solution at $\mathrm{pH} 5 \cdot 50 . T \mathrm{~F}=0.05 \mathrm{M} . T B=0 \cdot 20 \mathrm{M}$. Theoretical curves shown on the griph using $\tau / \epsilon=\gamma$ and $k=$ $1.76 \times 10^{12}: \kappa=\ldots . .1 .76 \times 10^{13}$.

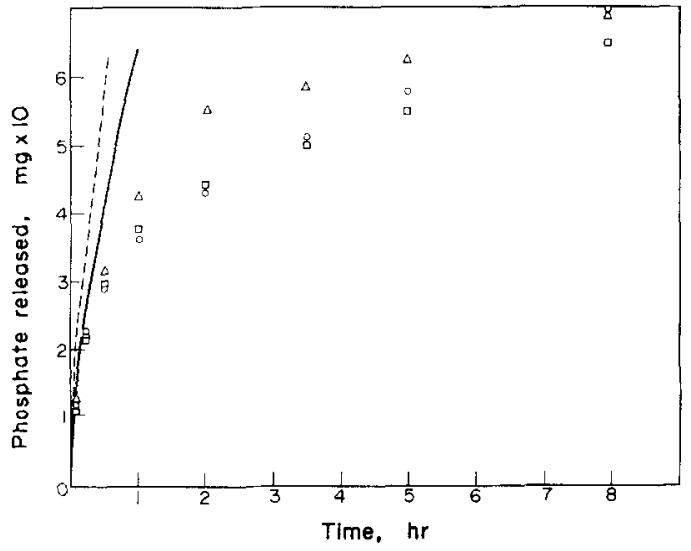

Fig. 11. Phosphate release from each of three enamel sections $\left(A=0.196 \mathrm{~cm}^{2}\right)$ on reacting with buffered fluoride solution at $\mathrm{pH} 5.00, T \mathrm{~F}=0.20 \mathrm{M}, T B=0.20 \mathrm{M}$. Theoretical curves shown on the graph using $\tau / \epsilon=8$ and $\kappa=$ $1.76 \times 10^{12} ; k=1.76 \times 10^{13}$.

simultaneously consistent with the physical model and with the conclusions deduced from the experiments with the synthetic TVA hydroxyapatite.

These findings strongly support the following conclusions.

1. The theoretical predictions of the model are reasonably accurate for initial reaction periods over a wide range of conditions.

2. The prevailing reaction conditions at $x=s$ are far from equilibrium predictions (i.e. $k=1.18 \times 10^{17}$ ). This is ascribed to both (a) a high supersaturation $\left(K_{\mathrm{CaF}_{2}}=10^{-8 \cdot 3}\right.$ vs $\left.K_{\mathrm{CaF}_{2}}=3.95 \times 10^{-11}\right)$ for calcium fluoride precipitation and (b) a significant undersaturation $\left(K_{A A P}=10^{-125}\right.$ to $10^{-127}$ vs $10^{-119}$ to $10^{-121}$ ) for apatite dissolution in the dynamic state.

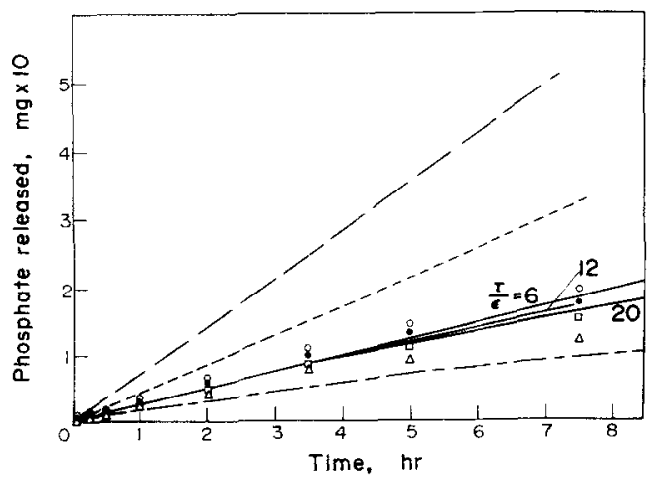

Fig. 12. Phosphate release from each of four enamel sections $\left(A=0.125 \mathrm{~cm}^{2}\right)$ with the membrane barrier on reacting with buffered fluoride solution at $\mathrm{pH} 5.50, T \mathrm{~F}=$ $0 \cdot 10 \mathrm{M}, T B=0 \cdot 10 \mathrm{M}$. Theoretical curves shown on the graph using various $k$ and $\tau / \epsilon$ values. $k=1.18 \times 10^{17}$ and $\tau / \epsilon=6 ; \quad=1.76 \times 10^{12}$ and $\tau / \epsilon=6.12$ and 20 ; - $k=3.74 \times 10^{\prime \prime}$ and $\tau_{i} \epsilon=6: \ldots . \quad k=$ $1.76 \times 10^{13}$ and $\tau / \epsilon=6$. 


\section{Possible mechanisms for the choking-off effect}

A possible explanation for the "choking-off" observed in these experiments is the following. If it is assumed that after the rapid initial reaction the subsequent reaction occurs with a large $\tau / \epsilon$ value, it is possible to explain the experimental data at later times. Estimates (Valvani, 1970) for $\tau / \epsilon$ were made by acid etching the enamel through the calcium fluoride layer. Values for $\tau / \epsilon$ of around tens to several hundreds were found under different conditions. Physically such large $\tau \epsilon$ values might arise if the calcium fluoride precipitates in such a manner to give a porosity much smaller than the theoretical value $(\epsilon \approx 0.25)$. That the greatest "choking off" is observed when the conditions favour the greatest supersaturation and therefore the most rapid nucleation is consistent with this view.

Observations with the scanning electron microscope (S. C. Valvani, W. I. Higuchi and J. J. Hefferren, unpublished) of the surfaces of enamel after the fluoride reaction support the interpretation that the "choking off" phenomenon might be explained largely by the mechanical blockage of diffusion pathways by the formation of a highly dense surface layer of calcium fluoride caused by the high super-saturation-rapid nucleation conditions. The SEM studies have shown that a very dense layer of fine particles is formed under low $\mathrm{pH}$ and high fluoride considerations.

The "choking off" might also be caused by the formation of some surface reaction barrier occurring after the relatively rapid initial phase of the reaction. Thus, the release and subsequent accumulation at the interface of some impurities might be considered partially responsible for the "choking off" effect. It is possible that these impurities may act as an inhibitor or "poison" for the reaction occurring at the solid-solid interface.

In contrast to these results with the enamel sections in fluoride solutions, the experiments involving synthetic hydroxyapatite discs (Nelson, 1968; Liang, 1971) were found to proceed "normally" as predicted by the physical model and no apparent "choking off" was observed.

Acknowledyement--This investigation was supported by a U.S. Public Health Service Grant DE-01830 from the
National Institute of Dental Research. National Institutes of Health, Bethesda, Maryland U.S.A.

\section{REFERENCES}

Desai S. J., Simonelli A. P. and Higuchi W., 1965. Investigation of factors influencing release of solid drug dispersed in inert matrices. J. pharm. Sci. 54, 1459-1464.

Farr T. D.. Tarbutton G. and Lewis H. T., 1962. System $\mathrm{CaO}-\mathrm{P}_{2} \mathrm{O}_{5}-\mathrm{HF}-\mathrm{H}_{2} \mathrm{O}$ : equilibrium at 25 and $50 \mathrm{C} . J$. Phys. Chem. 66, 318-321.

Gee A., Domingues L. P. and Deitz V. R.. 1954. Determination of inorganic constituents in sucrose solutions. Analyt. Chem. 26, 1487-1491.

Handbook of Chemistry and Physics 1969-70. (Edited by West R. C.) Chemical Rubber Co., Cleveland, Ohio. 50th Edn.

Higuchi W. I. and Higuchi T., 1960. Theoretical analysis of diffusional movements through heterogeneous barriers. $J$. Am. pharm. Ass.. Sci. Edn. 49, 597-601.

Hodes B., 1972. Dissolution rate studies of some calcium phosphates using the rotating disk method. Ph.D. Thesis, University of Michigan, Ann Arbor, Michigan.

Liang Zao-Shon, 1971. Kinetics and mechanism of fluoride uptake by hydroxyapatite. Ph.D. Thesis, University of Michigan, Ann Arbor, Michigan.

Liang Zao-Shon and Higuchi W. I., 1973. Kinetics and mechanism of fluoride uptake by hydroxyapatite. $J$. phys. Chem. 77, 1704-1710.

McCann H. G., 1968. The solubility of fluorapatite and its relationship to that of calcium fluoride. Archs oral Biol. 13, $987 \cdots 1001$.

Mir N. A., Higuchi W. I. and Hefferren J. J., 1969. The mechanism of action of solution fluoride upon the demineralization rate of human enamel. Archs oral Biol. 14, 901-920.

Nelson K. G., 1968. Studies on the rate of formation of calcium fluoride on hydroxyapatite in buffered solutions. Ph.D. Thesis, University of Michigan, Ann Arbor. Michigan.

Nelson K. G. and Higuchi W. I., 1970. Mechanism of fluoride uptake by hydroxyapatite from acidic fluoride solutions: I. Theoretical considerations. J. dent. Res. 49, 1541 1548.

Valvani S. C., 1970. The kinetics and mechanisms of reaction of tooth enamel in buffered solutions of high fluoride concentrations. Ph.D. Thesis, University of Michigan, Ann Arbor, Michigan.

Résumé - Les cinétiques et mécanismes de réactions de l'émail dentaire, soumis à des colutions tamponnées à concentrations élevées en fluor, ont été étudiés. Les résultats expérimentaux quantitatifs sont comparés avec la théorie basée sur un modèle physique représentatif de la réaction, ainsi qu'à des expériences utilisant des disques d'hydroxyapatite synthétique. Il s'avère que les valeurs initiales expérimentales se comparent bien avec les prédictions théoriques. Une analyse des résultats expérimentaux initiaux donne une constante de réaction $\kappa$, en ce qui concerne la dissolution des apatites et la précipitation de fluorure de calcium. L'auteur propose que la valeur de $\kappa$ est le résultat à la fois d'une supersaturation en fluorure de calcium et de sous-saturation en apatite au niveau des sites de réaction apatite-fluorure de calcium. Cette proposition cst conforme aux résultats obtenus avec des disques d'apatite synthétique. 
Des analogies importantes et des différences significatives sont notées entre les expériences réalisées avec des coupes d'émail et des disques d'apatite synthétique. Ces dernières expériences semblent se dérouler "normalement" sclon les prédictions du modèle physique pendant toute la réaction. Par contre, alors que les taux initiaux de la réaction émail-fluor varient relativement rapidement, en accord avec les prédictions théoriques, ces taux sont nettement diminués dans les phascs ultćrieures. Ce fait est particulièrement net dans les expériences menées à bas $\mathrm{pH}$ et à concentrations fluorurées élevées, et peu de variations sont observées à $\mathrm{pH}$ élevé et à faibles concentrations de fluor.

Zusammenfassung- Untersucht wurde die Kinetik und der Reaktionsmechanismus von Zahnschmel in gepufferten Lösungen mit hohen Fluoridkonzentrationen. Die experimentellen Ergebnisse wurden quantitativ ausgewertet und mit der Theorie auf der Basis eines die Reaktion repräsentierenden Modells sowie mit Untersuchungen unter Einschluß synthetischer $\mathrm{Hyd}$ roxylapatitscheiben verglichen. Es stellte sich heraus, daß die experimentellen Anfangswerte gut mit den theoretischen Erwartungen vergleichbar waren. Eine Analyse der experimentellen Anfangswerte führte zu einer Konstante $(k)$ für die Reaktion, welche die Apatitauflösung und den Kalziumfluoridniederschlag umfaßt. Es wird vorgeschlagen, daß der Wert $\kappa$ als Ergebnis der Übersättigung im Hinblick auf Kalziumfluorid wie auch der Untersättigung im Hinblick auf Apatit an den Orten der Apatit-Kalziumfluorid reaktion bewertet wird. Dieser Befund trifft auch für die Analyse der Experimente mit synthetischen Apatitscheiben zu.

Wichtige Ähnlichkeiten und bedeutende Unterschiede wurden zwischen den Experimenten mit Schmelzschnitten und mit synthetischen Apatitscheiben gefunden. Die Versuche mit synthetischen Apatitscheiben schienen entsprechend der Vorhersage anhand des physikalischen Modells über den gesamten Reaktionsverlauf hinweg "normal" abzulaufen. Im Gegensatz hierzu war die Schmelzfluoridreaktion in ihren späteren Abschnitten praktisch reduziert, während die Anfangswerte relativ schnell und entsprechend den theoretischen Annahmen abliefen. Dieser Befund erwies sich in den Versuchen bei niedrigem $\mathrm{pH}$ und hohen Fluoridkonzentrationen als am ausgeprägtesten, während dieser Effekt bei niedrigen Konzentrationen und hohem pH wenig oder gar nicht zu beobachten war. 